\title{
Tricho-retino-dento-digital syndrome
}

INSERM

\section{Source}

INSERM. (1999). Orphanet: an online rare disease and orphan drug data base. Trichoretino-dento-digital syndrome. ORPHA:1264

Tricho-retino-dento-digital syndrome is an autosomal dominant ectodermal dysplasia syndrome, characterized by uncombable hair syndrome (see this term), congenital hypotrichosis and dental abnormalities such as oligodontia (see this term) or hyperdontia, and associated with early-onset cataract, retinal pigmentary dystrophy, and brachydactyly with brachymetacarpia. Furthermore, hyperactivity and a mild intellectual deficit have been reported in affected patients. 